\title{
Numerical Simulation Analysis of Seismic of Frame Structure on Hill Terrain
}

\author{
Weisu Weng , Xupeng Zhao and Zhanxue Zhou \\ Hebei University of Architecture, 075000 Zhangjiakou, Hebei, China
}

\begin{abstract}
In recent year, Wenchuan,Ya'an,Yushu and other areas in china occur a series of high earthquake, however areas of earthquake is similar as mountainous terrain, building structure of seismic increasingly aroused our concern, and the research that hill topography affected building structure seismic in shallow mountain. The research content mainly includes: through modelling was built by the ANSYS software, the cooperative effects of a ten layer of frame structure- hill system were calculation. First, simple comparative dynamic characteristics analysis of soil - structure interaction and the rigid foundation assumption conditions; Second, put Hill-Soil-Structure Interaction(referred to as HSSI ) and Soil - Structure - Interaction(referred to as SSI) further analysis of the dynamic response, including: including structural modal analysis (vibration mode, cycle), the time history analysis (such as displacement, internal force and acceleration) and so on. Through Hill-Soil-Structure Interaction research, taking each factor in consideration, giving structure seismic key technology measures about shallow mountain to provide reference for such structure theory research.
\end{abstract}

\section{Introduction}

Our country is a vast land, but two-thirds of the area is mountain. With the growth of economy, urban land used by built construction does not meet the requirements of people to pursue a more healthy and comfortable environment, so the expansion of the city is imminent, therefore the development of the town is at its time. At the same time, with the adjoining hill land becoming more precious, the development of it is becoming more and more urgent. In engineering design, seismic research hill on building structures is lack of mature theory, so it may cause some unexpected risks of structural safety. For example: Many building structure is facing such a problem, is adjacent to mountain according to the design of the rigid ground assumption, which means there is no real consideration about hill and the role of its soil, simplified calculation program for analysis did not consider this part of the factors that could cause the internal forces of structure to reverse the sudden increase, these problems are not conducive to seismic design. Meanwhile, China is located between the Eurasian seismic belt and the Pacific Rim seismic belt, where seismic activity is so wide, and China is also an more and more seismic country, so the seismic design of frame structures for shallow mountain terrain should arouse our attention .So the analysis on such structures overall seismic is the most important issue for seismic areas.

Nowadays, the research of soil - structure interaction has made some achievements 1, but the application in practice is relatively less, and the analysis of hill - soil - structure is even fewer. Through theoretical study of HSSI issues, we will recognize the difference of the dynamic characteristics of the entire system and a single soil - structural; when the hill - soil - structure analysis is used as a whole, which is more different from the actual design of the structure, which is separated of the upper structure and rigid foundation. Therefore, the research fills up the deficiency of the theory, which provides us a reference for the future and the experience of the actual project.

\section{Principle of analysis model}

\subsection{The soil structure}

Soil structure is divided into two parts, one part is the soil which is at the bottom of the upper structure, the other part is the soil which is next to the upper structure of the hill. When often encountered or rarely met earthquake seismic action, the soil meets into the plastic zone. Considering the practical calculation of the analysis, this article mainly studies the effect of the hill and the structure, and reduce the process of calculation at the same time. Integrated all factors, the two parts of the soil both use ideal elasticity. So the results of the analysis is ideal, and we save much time for the calculation. Parameters of materials are as follows: elastic modulus of soil, poisson's ratio, density.

\subsection{The upper structure}


For the analysis of the upper structure, we adopt 2-D truss - layer mechanical model, which is built by the basic analysis unit, and to simplify the beams and columns for the neutral axis without mass, so the quality will be focused on each node, the DOF will be coherency by certain assumption, and the dynamic degree of freedom will be reduced, and the dynamic analysis will be carried out with in layer model. Duing to the greatness of the upper structure stiffness, compared with soil stiffness, the elastic analysis will be used.

\subsection{The overall model}

The soil structure model and the structure model are combined to form the whole stiffness matrix, mass matrix, and join Rayleigh damping, and to form the whole matrix. First, the step is going to analyse about static analysis; then, which are applied seismic action for the modal analysis and transient analysis.

Modal analysis is the analysis on the characteristic of structural natural vibration is used to determine the natural frequency and vibration mode of structure, the structure as the basis of transient analysis. Also can through the modal analysis preliminary judgment of the structure of the weak link, provide reference for further in-depth analysis.

And the time history analysis method is also known as direct dynamic method (or transient dynamics analysis), the modal analysis is further added, which is based on the dynamics equation of motion. Through the seismic time history curve as incentives, direct integral operation, to solve the dynamic response of each moment, including: displacement, stress and strain, acceleration, force, etc.

Any time of the whole model under earthquake action balance equation, the following formula:

$$
\begin{array}{r}
K \boldsymbol{u}(t)+C \dot{\boldsymbol{u}}(t)+M \ddot{\boldsymbol{u}}(t)=\boldsymbol{F}(t) \\
\boldsymbol{F}(t)=-M \ddot{\boldsymbol{u}}(t)
\end{array}
$$

Type: $K, C, M$, respectively represent the whole stiffness matrix, damping matrix of the whole, the overall quality of matrix; $\boldsymbol{F}(\mathrm{t})$ represent dynamic loading, $\ddot{\boldsymbol{u}}(\mathrm{t})$ represent he earthquake acceleration.

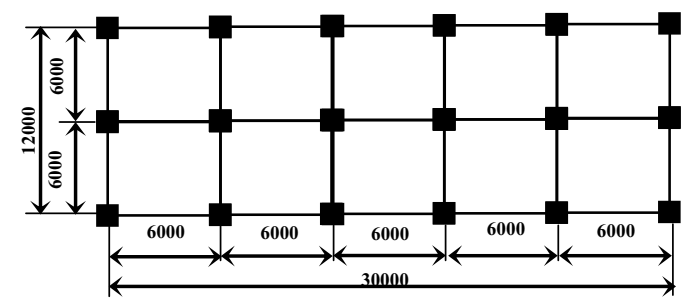

Figure 1. building plan

\section{Project summary}

A building structure system for cast-in-situ concrete frame structure, building standards plan is shown in Fig. 1. A total of ten layers structure, average height of $3 \mathrm{~m}$, span is $6 \mathrm{~m}$. Site casting thickness: $120 \mathrm{~mm}$, beam cross section: $250 \mathrm{~mm} 550 \mathrm{~mm}$, column section: 600 mmx600mm, concrete strength: C30, reinforced models: HRB400. Site category belongs to three classes, considering the seismic fortification intensity of 7 degrees often met earthquake $(0.15 \mathrm{~g})$.

\subsection{Model parameters}

Whole structure is simplified, Relevant data of the upper structure includes beams and columns using Beam 23 unit, the elastic modulus $\mathrm{E}=3.15 \times 10^{10} \mathrm{~N} / \mathrm{m}^{2}$, poisson's ratio $\mathrm{v}=0.3$, the damping ratio of concrete $\xi=0.05$, concrete density $\rho=2700 \mathrm{~kg} / \mathrm{m}^{3}$.

Soil of structure bottom: using Plane 42 , hill is $50 \mathrm{~m}$ deep.

Related introduction is as follows: BEAM23 unit is 2D plastic beam element, can have some property (tension- compression and bending bending capabilities), each node has three degrees of freedom, namely the translational motion displacement along the node coordinates $\mathrm{X}, \mathrm{Y}$ direction and rotation displacement around the $\mathrm{Z}$ axis.PLANE42 entity unit for a $2 \mathrm{D}$ structure, which is simulated entity structure plane. The element is used for graphic unit (plane strain and plane stress), and can be used for axisymmetric element. The unit has four nodes, each node has two degrees of freedom [2].

\subsection{The artificial boundary and damping}

In the soil-structure dynamic finite element time history, it is very important to select the appropriate finite soil on behalf of infinite field. In order to ignore the influence of the boundary of soil to structure, it needs to select part of the limited computing area in infinite field and choose the right size artificially. The soil boundary of the project model is greater than 10 times the length of one frame, which implements the scattering of soil boundary. This example uses the fixed constraints at the bottom of artificial boundary and restricts the vertical displacement at right and left, which meets the precision requirement.

In structural dynamic analysis, it is a key factor of damping selection in the process of the seismic capacity dissipation which caused by damping of the whole structure in the time course. ANSYS provides five kinds of damping. The results show that several kinds of damping effect on the structure is the same after comparing several damping. In order to simplify the calculation of structure form, this article chooses Rayleigh damping which has simple parameters setting. Firstly, extract the former two-class frequency based on modal analysis, which computes as:

$$
C=A M+B K
$$

where $\alpha$ is Alpha damper, also called mass damper; $\beta$ is Beta damper, also called stiffness and damping coefficients.

\subsection{Input seismic wave}

When the dynamic time history analysis is carried out on the building structure model, a reasonable choice of 
seismic wave analysis is a key factor to success. when choosing different seismic waves, the dynamic responses of the structure is very different; coupled with the randomness of the earthquake, so input a reasonable seismic wave is important. Referring to many research results show, seismic wave selected according to the site classification, through the use of China's code for seismic design of buildings GB50011-2010, an acceleration peak value change processing, simplified calculation formula and also meet the accuracy requirements, reflecting the real dynamic response of the structure .Using Ning heTianjin's seismic waves have been record, he peak acceleration is: $=104 \mathrm{~cm} /$, The time interval is: $0.01 \mathrm{~s}$, The duration time is $19.2 \mathrm{~s}$. Input Seismic wave in the $\mathrm{X}$ direction, Acceleration adjustment formula is as follows:

$$
a^{\prime}=\frac{A_{\max }^{\prime}}{A_{\max }} a(t) .
$$

\section{Interaction analysis of model}

The soil - structure interaction seismic calculation and model history analysis method of the calculation process is as follows [4]: (1) consider the weight of structure, the static analysis (ANTYPE, STATIC);(2) under the condition of without considering gravity, modal analysis (ANTYPE, MODAL);(3) the last transient analysis (ANTYPE, TRANS).Applying acceleration for the elastic analysis in static analysis; In modal analysis, extracting the model cycle to transformation period for the angular frequency, then prepare the way for applying damping at the back of the time history analysis; On the basis of the first two steps, the last time history analysis, after the input amplitude modulation of earthquake acceleration, structural damping parameters and Rayleigh damping. Applying level $\mathrm{X}$ vibration direction, analysis of three different calculation models respectively design calculation, specific parameters are shown in Table 1 below, model shown in figure.

Table 1. Different parameters of calculation models

\begin{tabular}{|c|c|c|c|}
\hline Group & Model 1 & Model 2 & Model 3 \\
\hline Model type & $\begin{array}{c}\text { Rigid } \\
\text { foundation } \\
\text { assumption }\end{array}$ & Soil- structure & $\begin{array}{c}\text { Hill-soil- } \\
\text { structure }\end{array}$ \\
\hline Difference & $\begin{array}{c}\text { The bottom of } \\
\text { the column } \\
\text { uses rigid } \\
\text { connection }\end{array}$ & $\begin{array}{c}\text { Infrastructure } \\
\text { is a deep soil } \\
\text { (deep } 50 \mathrm{~m}\end{array}$ & $\begin{array}{c}\text { There were } 10 \mathrm{~m} \\
\text { away from the } \\
\text { structure, and } \\
\text { high } 20 \mathrm{~m} \text { *long } \\
100 \mathrm{~m} \text { hill }\end{array}$ \\
\hline
\end{tabular}

\subsection{Cycle analysis of structure model}

Through the modal analysis, the first 5 orders of the three models are listed, as follows Table 2. Observed under the same vibration type, different model simulations are more accurate and more close to the engineering, then longer period of the structure; At the same time by two cycles ratio index $\left(T_{2} / T_{1}, T_{3} / T_{2}\right)$ shows, the cycle of model 1 and model 2 significantly increased due to considering the impact of soil; and model 2 and model 3 compared to the

former increased slightly because of considering the hill. On the whole, the period of the hill-soil structure is much larger than that of the rigid ground hypothesis. The main reason is that relative to the upper structure, the foundation soil and hill has a trend of mutual movement, while compared to the rigid foundation model, the overall stiffness and damping of the overall analysis model became larger, and thus the cycle becomes longer.

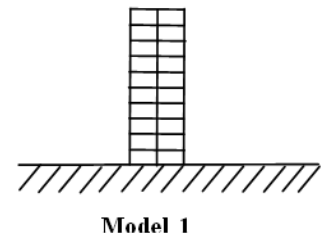

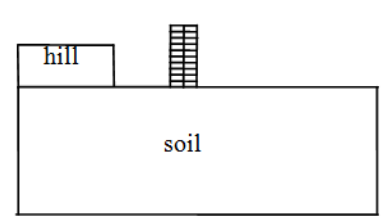

Model 1

Figure 2. Calculation's model

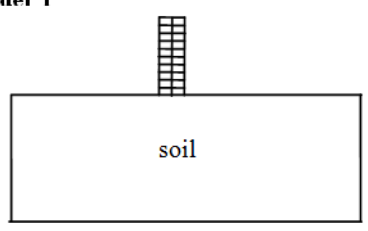

Model 1

Table 2.Three model cycle

\begin{tabular}{|c|c|c|c|c|}
\hline Mode of vibration & $\mathbf{1}$ & $\mathbf{2}$ & $\mathbf{3}$ & $\mathbf{4}$ \\
\hline$T_{1}(\mathrm{~s})($ Model 1$)$ & 4.6594 & 1.3727 & 0.6773 & 0.3957 \\
\hline$T_{2}(\mathrm{~s})($ Model 2$)$ & 6.0194 & 1.6743 & 0.9140 & 0.7990 \\
\hline$T_{3}(\mathrm{~s})($ Model 3$)$ & 6.0194 & 1.6752 & 1.2906 & 0.8452 \\
\hline$\left(T_{2}-T_{1}\right) / T_{1}$ & 0.2914 & 0.2197 & 0.3494 & 1.0180 \\
\hline$\left(T_{3}-T_{2}\right) / T_{2}$ & 0.0000 & 0.0006 & 0.4120 & 0.0578 \\
\hline$\left(T_{3}-T_{1}\right) / T_{1}$ & 0.29188 & 0.2204 & 0.9054 & 1.1363 \\
\hline
\end{tabular}

\subsection{The acceleration and displacement analysis of top structure}

Fig. 3 shows three acceleration curves of top-level structure system, the largest acceleration of the rigid foundation (Model 1) is $0.497 \mathrm{~m} / \mathrm{s}^{2}$, and the maximum acceleration of soil-structure system for $0.519 \mathrm{~m} / \mathrm{s}^{2}$, while the hill-soil-structure (with the model of the closest actual situation) maximum acceleration is $0.534 \mathrm{~m} / \mathrm{s} 2$; the maximum acceleration of model 2 is more than that of model 1 by $5.633 \%$, and less then that of model 3 by $1.685 \%$ The acceleration curve of the rigid foundation is assumed to be slower than the other two, and the main factor is the existence of soil damping. The Through the modal analysis, the first 5 orders of the three models amplitude variation of acceleration time history curve of model 2 and model 3 is basically the same, which shows that the influence of soil on structure can not be ignored in practical engineering.

Fig. 4 shows three top-level displacement curves of these models, rigid foundation during the whole time history analysis, which compared to displacement trend of model 1 and model 2 in the most of the time,corresponding to the maximum, The datum indicates that soil of stiffness and damping matrix has decreased the top displacement of the structure, the soil can not be 
ignored influence of the top displacement of the upper structure .The maximum displacement ratio of model 3 is larger than that of model 2 by $16.43 \%$, which shows that compared to the soil structure model, the existence of the hill cause the trend of the large displacement. In the whole history, the rigidity foundation reach the peak of the maximum displacement is relatively fast, and the existence of hill is the main reason that model 3 is slightly slower than the model 2 .

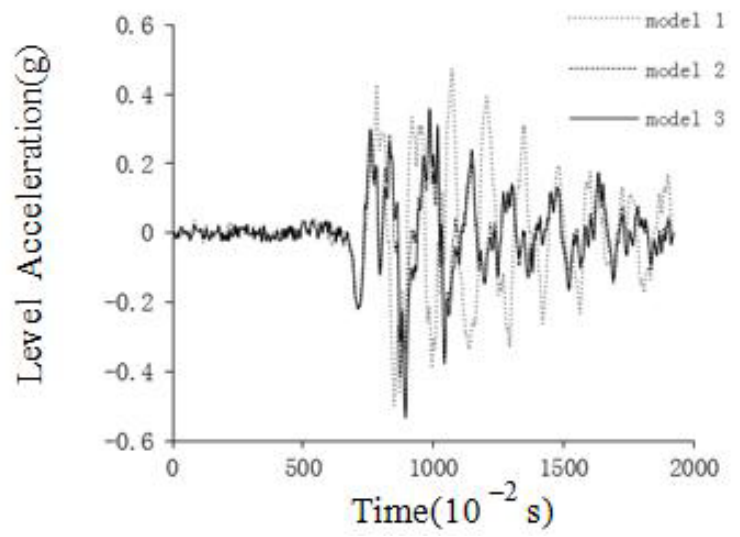

Figure 3. The acceleration curve of top-level

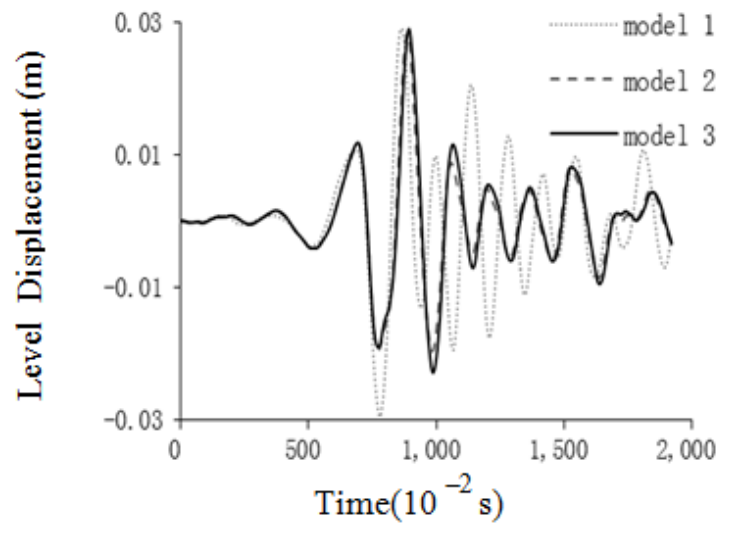

Figure 4. The displacement curve of top-level

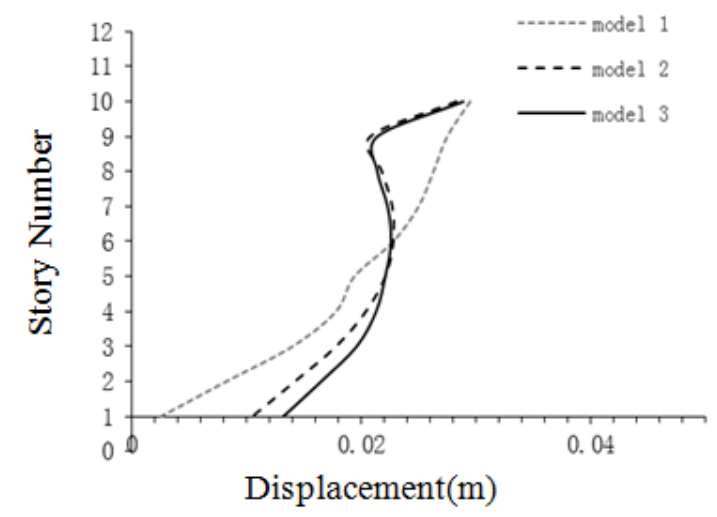

Figure 5. Layer displacement
Layer displacement of three models as shown in Fig. 5 , it can be seen that the existence of the soil and scarp from three curves roughly changes, and the maximum layer displacement of 6th-10th floor have mutation, which is less than that of corresponding layers compared to the rigid foundation; structure of the layers below, layer displacement spurt, top layer shift basis unchanged to the present.

\section{Conclusions}

In seismic performance analysis of building structure, the whole model response more realistic the stress characteristics of the structure, embodies an interaction between one upper,lower structure and the surrounding environment.In this paper,three different models under the action of vertical load and horizontal dynamic load make the numerical simulation, analyzes the influence on the upper structure under the existence of hill.Through analysis, compare, and summarize, the conclusions as follows:

(1) Through the comparative analysis of three model, the cycles of model one, two, three are gradually increasing, the main reason is the involvement of the hill and soil, compared with the rigid ground assumption ,model stiffness decreases, lead to the overall structure become soft,which is in favor of the seismic energy dissipation

(2) Considering the hill - soil - structure dynamic time history analysis, because of the existence of scarp and flexible foundation layer, top displacement and displacement of the upper structure acceleration has a different degree of influence.Under the overall modeling analysis,there is a difference with rigid foundation assumption ,actual hill, soil influence on the structure cannot be ignored.

(3) Considering the scarp - soil - structure interaction is a very complex tedious study, as the limitation of the time and research conditions, this case is simply analyzed the influence of the hill, provide a reference for engineering design, as well as the subsequent researchers.

\section{References}

1. Zhan-xue. Zhou, Li-jun. Wang, Yan-tao, Li, Hai-yang. Feng, JOURNAL OF HEBEI INSTITUTE OF ARCHITECTURAL SCIENCE \& TECHNOLOGY, Seismic,responses on str-ucture-basements-piIes-soil interaction, 40,4(2005)

2. Hong-nan. Li, guo-xing. Chen, Earthquake Engin eering: China Machine PRESS (2013)

3. GB50011-2010.Code for Seismic Design of Buildings: China Building Industry Press (2010)

4. Xin-min. Wang, Numerical Analysis of ANSYS Engineering Structure: China Communications Pr-ess (2007). 